\title{
A Rare Solitary Fibrous Tumour of Kidney
}

\author{
Tilak Bahadur Pathak, 'Umesh Nepal' \\ 'B.P. Koirala Memorial Cancer Hospital, Bharatpur, Chitwan, Nepal.
}

\begin{abstract}
A solitary fibrous tumour is an unusual spindle cell neoplasm. It frequently arises from the serosal surface of pleural cavity but has recently been described in diverse extrapleural sites. Urogenital localization is rare and only 36 cases of solitary fibrous tumours of the kidney have been described on published report. We report a case of a large solitary fibrous tumour clinically and radiologically thought to be renal cell carcinoma arising in the kidney of a 30 year old female. The radical nephrectomy was performed. The tumour was a well- circumscribed, solid mass attached to the renal pelvis without necrosis and haemorrhage. Histopathologically, a spindle cell neoplasia with alternating hypo and hypercellular areas, storiform, fascicular and hemangipericytoma like growth pattern and less cellular dense collagen deposits were observed. Immunohistochemical studies revealed reactivity for $\mathrm{CD} 34, \mathrm{CD} 99$ and Bcl-2 protein.
\end{abstract}

Keywords: immunohistochemistry; kidney; solitary fibrous tumour.

\section{INTRODUCTION}

The Solitary Fibrous Tumor (SFT) is an unusual spindle cell neoplasm first described in the pleura, in 1870, by Wagner. ${ }^{1}$ Postulated cells of origin comprise of fibroblasts, myofibroblasts, endothelial cells, as well as pericytes. ${ }^{2}$ This type of tumour usually arises from pleura but has recently been described in diverse extrapleural sites like upper respiratory tract, lung, nasal cavity, paranasal sinuses, orbits, mediastinum, major salivary glands, breast, meninges, liver and urogenital organs. ${ }^{3,4}$ SFT is very rare in kidney and only 36 cases of SFTs are published in literatrure. ${ }^{5}$ No such case is reported from Nepal so far.

\section{CASE REPORT}

A 30 year old Nepalese woman presented with a history of right flank mass without hematuria. Physical examination revealed bimanually palpable mass in right flank. Preoperative laboratory findings were within normal range. Ultrasonography (USG) showed a hyperechoic mass of $94 \times 72 \mathrm{~mm}$ in right kidney with hypervascularity. Corticomedullary differentiation was normal.

Computed Tomography (CT) scan of the abdomen demonstrated a well delineated, encapsulated, contrast enhanced mass measuring $85 \times 75 \times 65 \mathrm{~mm}$ in medial aspect of right kidney extending superiorly from renal hilum. Renal vein and Inferior venacava (IVC) were free of tumour. With pre-operative diagnosis of renal cell carcinoma, radical nephrectomy was performed. Intraoperative and post-operative period were uneventful.

Pathological finding:

Grossly specimen showed a well-circumscribed encapsulated, firm solid mass originating from renal pelvis (Figure1). The tumor had a firm grey white cut surface. No necrosis and hemorrhage was identified on gross examination. Microscopically tumour consisted of

Correspondence: Dr. Tilak Bahadur Pathak, B.P. Koirala Memorial Cancer Hospital, Bharatpur, Chitwan, Nepal, Email: pathaktilak@ hotmail.com, Phone: 9845276303. 
hypercellular and hypocellular areas (Figure 2). Tumour was composed of spindle cells without obvious growth pattern. Tumour cells were arranged in haphazard storiform, short fascicular and hemangiopericytoma like growth pattern and less cellular dense collagen deposits were observed. These cells had small ovoid to spindle shaped nuclei with indistinct cytoplasmic border. Mitotic activity and necrosis were not observed. Immunohistochemical studies revealed diffusely positive for vimentin, CD34, CD99 and Bcl-2 protein (Figure 5) and negative for Smooth muscle antigen, desmin, S100 and CD117.On the basis of histological and immunohistochemical findings, we made a final diagnosis of solitary fibrous tumor of kidney.
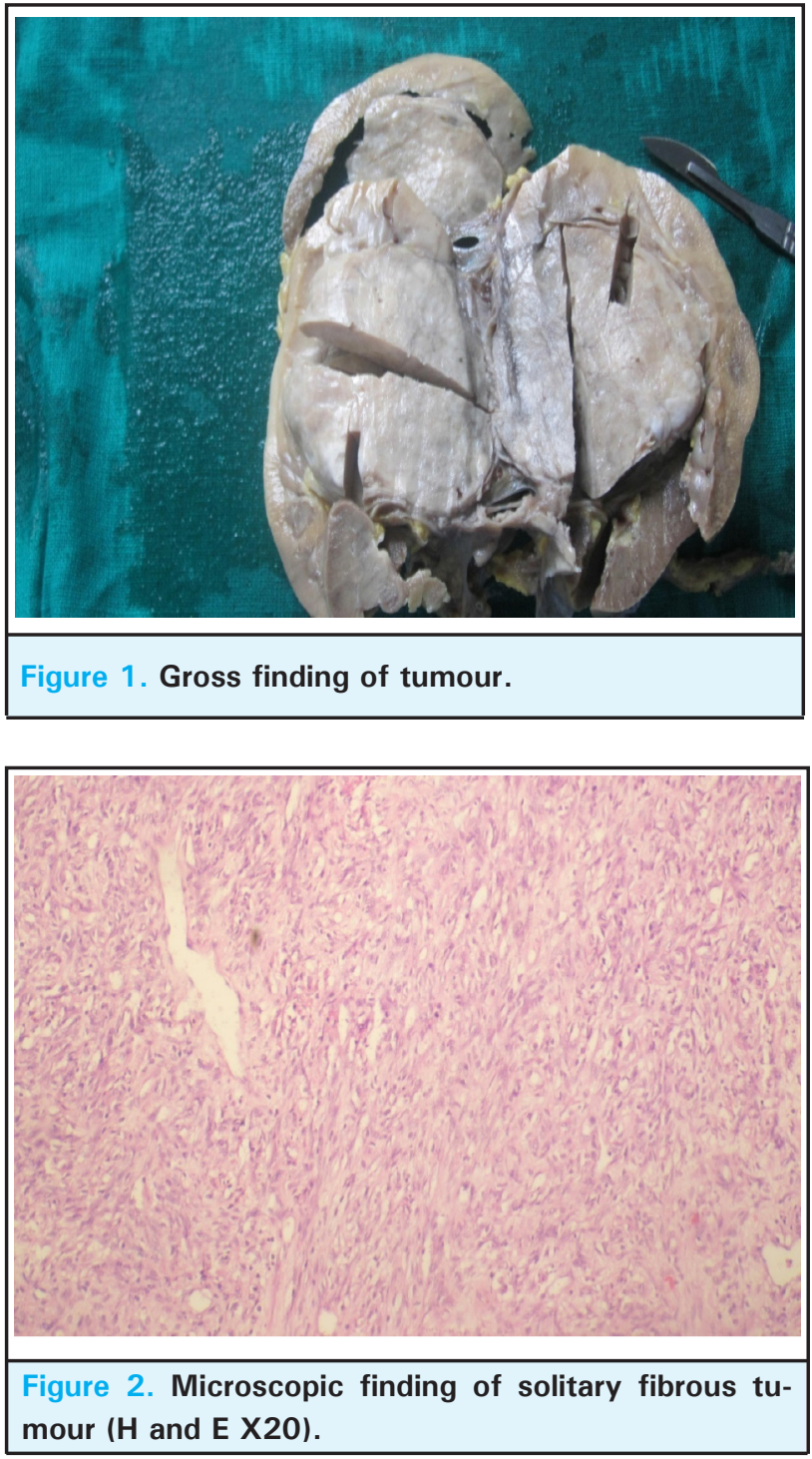

\section{DISCUSSION}

Solitary fibrous tumours are rare mesenchymal tumour, arise most frequently in the pleura; however, occurrences of these tumours at sites other than the pleura have been described in recent years. ${ }^{3}$ First renal SFT has been reported by Gelb et al in $1996 .{ }^{6}$ These tumours arise most frequently from the serosal layer of pleura; however, occurrence of these tumours at sites other than the pleura have been described in recent years. The kidney is a relatively infrequent site for SFT, with at least 36 cases reported in a review article. ${ }^{5}$ Only one case was reported in renal pelvis from Japanese literature There has been no reported case of SFT in the kidney in published literature from Nepal.

In general, they are slow growing benign lesions and characteristically exhibit diffuse CD34 positivity. This case study described an SFT arising in the renal pelvis. The final diagnosis was made by immunohistochemical study using a monoclonal progenitor cell antigen (CD34) stain. Almost all renal SFT are seen in middle-aged with wide range (18-85) of age and more common in women. The most frequent clinical findings are abdominal or flank pain. Occasionally abdominal/flank mass or hematuria can be seen. In our case patient presented with abdominal lump without hematuria. Tumours vary in size reported in the literature ranging from 2 to 25 $\mathrm{cm}$ (mean $8.75 \mathrm{~cm}$ ). ${ }^{5}$ In our case it is comparative with mean size of tumour.

Macroscopically, renal SFT are classically well circumscribed, lobulated rubbery to firm, solid mass with homogenous grey or tan-white. On cut surface, whorled appearance without necrosis, haemorrhage and cystic changes. Our case showed similar classical findings and mass arises from renal pelvis without involvement of ureter and renal capsule.

In all the reported cases of SFT of the kidney, final diagnosis was made by means of histopathology and immunohistochemical analysis. In our cases we made diagnosis on morphological basis and confirmed by immunohistochemistry.

Microscopically, benign SFTs consists of hypocellular and hypercellular areas, tumours are composed of spindle cells without an obvious growth pattern, so called pattern less pattern. SFTs are tumours with variable cellularity and composed of a mixture of haphazard, storiform, short fascicular arrangements of bland spindle cells and collagenous bands. Spindle cells are not atypical and have little cytoplasm with indistinct borders. Mitosis is rare and mast cells and lymphocytes can be seen occasionally. Most of the SFTs are histologically benign, there are malignant SFTs are reported in the literature. ${ }^{8}$ Malignant behaviours in the forms of recurrence and metastases can occur in 10 to $15 \%$ of intrathoracic SFTs and up to $10 \%$ of extrathoracic SFTs. ${ }^{9}$

Immunohistochemically diffuse vimentin and CD34 
positivity are seen most of the SFTs tumors. ${ }^{3,4,10}$ CD34 and CD99 positive in $90-95 \%$ and $70 \%$ in SFTs respectively. ${ }^{11} \mathrm{Bcl}-2$ expression in SFTs is found in various degree (20-35\%) in different studies. . 5,10 In our cases Vimentin, CD99, CD34 and $\mathrm{BCl}-2$ were positive in tumour cells. S100, smooth muscle antigen and desmine were negative.

Prognosis of SFTs is generally good and most of these tumours are non- recurring and non-metastasing tumours. Approximately $10-15 \%$ of SFTs behave aggressively; thus long term follow up is mandatory. ${ }^{3}$
Only one case of previously reported 36 renal SFT has been reported as malignant, but unfortunately followup information was not available for this case. ${ }^{11}$ In our case, patient came for follow up after three months of surgery and she is fine without any complaints.

In conclusion, solitary fibrous tumour in kidneys, though very rare can be encountered in our clinical practice. Management is same as that for any solid renal tumor but histopathological diagnosis depends on Immunohistochemistry.

\section{REFERENCES}

1. Bouhabel S, Leblac G, Ferreira J, Leclerc YE, Dube P, Sideris L. Solitary fibrous tumor arising in the mesentry: a case report. World J Surg Oncol. 2011 Oct 31;9:140.

2. Gengler C, Guillou L. Solitary fibrous tumor and haemangiopericytoma: evolution of a concept. Histopathology. 2006 Jan;48(1):63-74.

3. Znati K, Chbani L, Fatemi H E, Harmouch T, Kamaoui I, Tazi $\mathrm{F}$, et al. Solitary fibrous tumor of the kidney: A Case Report and Review of the Literature. Rev Urol. 2007;9(1):36-40.

4. Naveen HN, Nelivigi GN, Venkatesh GK, Suriraju V. A case of solitary fibrous tumor of the kidney. Urol Ann. 2011;3(3):158-60.

5. Magro G, Emmanuele C, Lopes M, Vallone G, Greco P. Solitary fibrous tumor of the kidney with sarcomatous overgrowth. Case report and review of the literature. APMIS. 2008 Nov;116(11):1020-5.

6. Gelb AB, Simmons ML, Weidner N. Solitary fibrous tumor involving the renal capsule. Am J Surg Pathol. 1996 Oct;20(10):1288-95.

7. Yazaki T, Satosh S, Lizumi T,Yamaguchi Y. Solitary fibrous tumor of renal pelvis. Int J Urol. 2001 Sept;8(9):504-8.

8. Fine SW, McCarthy DM, Chan TY, Epstein JI, Argani P. Malignant solitary fibrous tumor of the kidney: report of a case and comprehensive review of the literature. Arch Pathol Lab Med. 2006 Jun;130(6):857-61.

9. Hsieh TY, ChangChien YC, Chen WH, Chen SC, Chang LC, Hwang CC, et al. De novo malignant solitary fibrous tumor of kidney. Diagnpathol. 2011 Oct;6:96.

10. Kohl SK, Mathews K, Baker J. Renal Hilar Mass in an 85-year-old woman. Solitary fibrous tumor. Arch Pathol Lab Med. 2006 Jan;130(1):117-9.

11. Kurt B, Öngürü Ö, Özcan A, Çiçek AF, Başal Ş, Örs F, et al. Solitary fibrous tumor of kidney: a case report with extensive review of the literature. GMJ. 2009;51:116-21. 